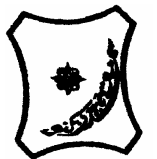

Bayero Journal of Pure and Applied Sciences, 4(1): 44 - 47

Received: November, 2010

Accepted: May, 2011

ISSN 2006 - 6996

\title{
PREVALENCE OF INTESTINAL HELMINTHES OF DOGS THAT HAVE BEEN DISPOSED OFF AT NON-DESCRIPT ABATTOIRS IN ZARIA, NIGERIA
}

\author{
${ }^{1}$ Ugwoke, E V., ${ }^{* 1}$ Audu P.A., ${ }^{2}$ Umoh J.U and. ${ }^{1}$ Adakole J.A \\ ${ }^{1}$ Department of Biological Sciences, Ahmadu Bello University, Zaria, \\ ${ }^{2}$ Department of Veterinary Public Health and Preventive Medicine Faculty of Veterinary Medicine Ahmadu Bello \\ University, Zaria, \\ *Corresponding author
}

\begin{abstract}
Parasitological investigation of dogs disposed off in non-descript abattoirs was carried out in two communities (Basawa and Angwagodo) in Zaria. Intestines from seventy (70) adult dogs were collected, and standard procedures were followed to determine their parasite loads. A total of sixty-three dogs (90.00\%) were positive for different species of helminthes. The helminthes recovered were Dipylidium caninum, Taenia spp, Ancylostoma caninum and Toxocara canis. $D$. caninum was present in thirty five dogs $(50.00 \%)$, Taenia spp in twenty dogs $(28.57 \%)$. Ancylostoma caninum in twenty five dogs (35.71\%) and Toxocara canis in four dogs $(5.71 \%)$. There were no statistically significant associations between the location of study and frequency of recovery of each helminthes $(P>0.05)$. Toxocara canis was only detected at Angwagodo. The mean

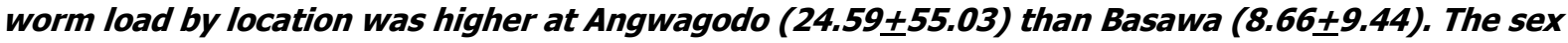
of the dog had no significant effect on the recovery of each helminthes $(P>0.05)$. However, female dogs had a higher worm load (22.14 \pm 57.41$)$ than the male dogs (12.12 \pm 18.44$)$. The result of this study suggests that about $90 \%$ of the dog population in Zaria may be contributing to the contamination of the environment with eggs of zoonotic helminthes.
\end{abstract}

Key words: Intestinal helminthes, Dogs, Non-descript Abattoirs, Zaria.

\section{INTRODUCTION}

Canis familaris (dogs), which first became domesticated in the Middle East and dates to around $12,000-14,000$ years ago. Based on current archeological evidence, by Savage cave man is considered the closest animal to man (Olori, 2008). Dogs serve humans in so many ways. In spite of its usefulness, dogs especially stray dogs are sources of danger to human health. Their wide feeding habits and sources of food make them to pick up or harbor helminthes parasites some of which affect humans (Umar, 2009).

Helminthes parasites harm their hosts by mechanical damage, devouring of tissues or loss of blood and toxic effects. Humans get infected through contact with infected dog faeces or contaminated soil (Amin, 2002). Such helminthes pathogens include Ancylostoma caninum, Taenia spp, Dipylidium caninum, Ascaris spp, Isospora canis, Toxocara canis, Echinococcus granulosus etc (McCarthy and Moore, 2000; Robertson et al., 2000, Adebote et al., 2000).

Human infection with certain helminthes of dogs may lead to acute and chronic problems of public health importance. Prevalence rate of the disease caused by these parasites are on the increase in line with the increase in dog population (Carl, 1988). Thus, it has been known that certain intestinal helminthes of dogs are responsible for some diseases in humans. Therefore, there is a need to study the prevalence of these pathogens.
The importance of dogs to man are so numerous, they have adapted themselves to economic usefulness, they serve as hunting dogs, guard dogs and herding dogs. Dogs have served as guides for the blinds. In certain cultures, dogs are raised and slaughtered as a source of meat; dogs are popular as pets and companion (Kim, 2008; Murray, 2007 and Dog meat Wikipedia, 2010.). On the other hand, dogs have been a source of danger to humans through their bites, and as transmitters of zoonotic diseases like rabies, toxoplasmosis, echinococcosis, trypanosomiasis, filariasis, spirocerosis, hydatidosis, larva migrans and other diseases (WHO, 1959; Oduyemi and Olayemi, 1977; Hill et al., 1985). They also contaminate the environment with their faeces.

A large proportion of dogs in Nigeria are ownerless especially in large cities. They roam about feeding on refuse dumps, picking up offal in abattoirs, coming in contact with wide animals where they get infected with some parasites. It is estimated that Nigeria has about 4.5 million dogs (Fasanmi, 2004). Thus, Nigeria may be estimated to have over 12 million dogs between the years $2005-2007$. The dog population in Nigeria continues to increase (Olufemi and Bodabe, 1979; Ezeokoli, 1984 and Fasanmi, 2004) with corresponding increase in the spread of the disease. With the knowledge of intestinal helminthes of dogs, the extent of possible contamination of the environment with their faeces, which contain infective eggs or infective larval stages, could be assessed. 


\section{MATERIALS AND METHODS \\ Sources of Samples}

Samples were obtained from stray dogs, dogs from homes, apprehended from different parts of Zaria which are disposed off at non-descript abattoirs around Zaria, Kaduna state.

\section{Processing of Samples}

Seventy of intestine samples were collected during the period of study. After slaughter, the entire intestinal tract, which includes small and large intestines were retrieved and placed in clean labeled polythene bags. The samples were transported immediately to the laboratory.

The history of the dogs were obtained and recorded. In the laboratory, each of the intestinal tracts was cut open longitudinally in an anterio-posterior position with scissors. The contents were discharged into a pan. The mucosal linings were scraped into the pan because some parasites penetrate the lining. Care was taken to collect all the washings and ingesta. Water was added in large quantity and then stirred. The supernatant fluid was decanted by filtering through a laboratory test sieve of $200 \mathrm{~mm}$ diameter. The washing was repeated until the supernatant fluid became clear. The content was then transferred into a Petri dish, and then into a clean appropriately labeled bottle containing $10 \%$ formalin. This process was repeated for all the samples that were collected. After the collection of the samples into separate bottles, each of the samples was poured into a Petri dish a little at a time and scanned under a magnifying glass. The parasites observed were removed from the sediment and were classified based on their morphological characteristics.

\section{Identification of Parasites Isolated}

Most of the parasites were identified by macroscopic features but all the worms were subjected to microscopic examinations as well. The preserved worms were mounted on a slide and three drops of lacto phenol was added. Apart from clearing worms, the lacto phenol made the worms to be stretched out facilitating the study of the relevant organs for proper identification. The identification was done using a standard text and was further confirmed in the Helminthology Unit of the Department of Veterinary Parasitology and Entomology, Ahmadu Bello University, Zaria.

The results obtained were statistically analysed by comparing the prevalence of parasites in the two locations, and in the sex group using the Statistical Package for Social Science (SPSS) software. Odds Ratio and Chi-square were calculated to check for association between location, sex and the occurrence of helminthes.

\section{RESULTS}

The overall infection rate of dogs disposed off at nondiscrete abattoirs in Zaria was $90 \%$ Table 1 shows that 63 of the 70 samples of intestine examined were infected with different species of helminthes. Out of 36 samples of intestines of dogs from Basawa examined, 33(91.70\%) were infected, and for 34 samples from dogs in Angwangodo, 30(88.20\%) were infected. The difference in infection rate between the two locations (Basawa and Angwangodo) was not statistically significant ( $P \square 0.05)$. The infection in the male dogs $(90.20 \%)$ was higher than in the female dogs $(89.70 \%)$ (Table 2), though this was not significantly different ( $P \square 0.05$ ). With respect to the types and distribution of parasites in the infected dogs, Dipylidium caninum, a cestode was the most common helminth encountered. The overall infection rate for Dipylidium caninum, Taenia spp, Ancylostoma caninum and Toxocara canis were $50.00 \%, 26.10 \%$, $35.70 \%$ and $5.75 \%$ respectively (Table3). Table 4 shows that single infections were most prevalent. The prevalence rate for single, double and triple infections were; $61.40 \%, 27.40 \%$ and $1.40 \%$ respectively.

Table 1: Intestinal Helminthes infection in Dogs Disposed off at Non-Discrete Abattoirs in Zaria by Location.

\begin{tabular}{lccc}
\hline Location & Number Examined & Number positive & Percentage positive (\%) \\
\hline Basawa & 36 & 33 & 52.38 \\
Angwagodo & 34 & 30 & 47.62 \\
\hline Total & $\mathbf{7 0}$ & $\mathbf{6 3}$ & $\mathbf{9 0 . 0 0}$ \\
\hline
\end{tabular}

( $\mathrm{t}=-1.688, \mathrm{P} \square 0.05$ (Not significant) $\quad \mathrm{OR}=0.87$ (No association).

Table 2: Intestinal Helminthes infection in Dogs Disposed off at Non-Discrete Abattoirs in Zaria by Sex.

\begin{tabular}{lccc}
\hline Sex & Number Examined & Number Positive & Percentage positive (\%) \\
\hline Female & 29 & 26 & 42.27 \\
Male & 41 & 37 & 58.73 \\
\hline Total & $\mathbf{7 0}$ & $\mathbf{6 3}$ & $\mathbf{9 0}$ \\
\hline
\end{tabular}

$\mathrm{t}=-1.046, \mathrm{P}=0.299$

Table 3: Types and Distribution of Parasites in the infected Dogs in Zaria.

\begin{tabular}{lcc}
\hline Parasites & Number Positive & Percentage positive (\%) \\
\hline Cestodes: & 35 & 50.00 \\
Dipylidium caninum & 20 & 28.57 \\
Taenia Spp & & \\
Nematodes: & 25 & 35.71 \\
Ancylostoma caninum & 4 & 5.71 \\
Toxocara canis & & \\
\hline
\end{tabular}


Table 4: Intestinal Helminthes infection in Dogs Disposed off at Non-Discrete Abattoirs in Zaria in relation to type of Infections.

\begin{tabular}{lcc}
\hline Type of Infections & Frequency & Percentage (\%) \\
\hline Single & 43 & 61.43 \\
Double & 19 & 27.41 \\
Triple & 1 & 1.43 \\
\hline Total & $\mathbf{6 3}$ & $\mathbf{9 0}$ \\
\hline
\end{tabular}

\section{DISCUSSION}

The study has revealed a high level (90\%) of helminthes infections in the dogs disposed off at non discrete abattoirs in Zaria. The dogs came from Samaru, Sabon gari and the surrounding villages. The infections observed in the study could have emanated from the unhealthy feeding habits of dogs coupled with poor sanitation (Traub et al., 2002), and poor supervision and control of dogs around the area by the owners.

Male and female dogs were almost equally prone to infection. Both were equally responsible for the contamination of the environment.

Multiple infections with the different helminthes parasites were common in the dogs examined suggesting that a dog may act as a reservoir of more than one zoonotic intestinal parasites, and are of high health risk to their owners and other people.

Dipylidium caninum is the most common dog parasite in most part of the world (Soulsby, 1968 and Smyth, 1994). Its high prevalence in this study could be due to the increase in strays that generally do not receive any type of antiparasitic treatment. The importance of this lies in the zoonoses reported mainly in children (Gavignet, 2008). The occurrence of Taenia species could also be a source of infection for some domestic animals and potentially hazardous to the human health.

In the case of the nematodes, Ancylostoma caninum had a high prevalence $(35.71 \%)$ this was as reported in other studies (Flores and Uruchurtu, 1977; Levine, 1980; Fabiyi, 1983; Tekdek and Umoh, 1985; Schad, 1994; Komtangi, 1998 and Adebote et al., 2002). Its high prevalence could be due to the high resistance of the eggs. Also nematodes have a thick cuticle around

\section{REFERENCES}

Adebote, D.A., Oniye, S.J. and Adegboyega F.S. (2002). Eggs and cyst of parasites in faecal samples of household dogs (Canis familaris) in Zaria. Nigerian Journal of Pest, Disease and Vector Management, 4:285-289.

Amin, O.M., (2002). Understanidng parasites. Parasitology center, Incoperated. (PCI) Tempe Arizona.

Anderson, R.M. (1993). Epidemiology. In: Cox F .E.G.. (Ed); modern parasitology. Blackwell Scientific Publications, London, P.276.

Carl, E. K. (1988). Epizootiologyof endoparasitic infections in pest dogs and cats Presented to a Veterinary Teaching Hospital. Veterinary Parasitology, 30: 113-124. them which might serve as a form of adaptation to parasitism. This helps them to survive unfavorable conditions, such as the digestive enzymes inside the host. Despite the fact that Toxocara canis have these features, the prevalence of this nematode was lower and this can be explained by the fact that it is found mainly in puppies (Hill et al., 1985). Out of the seventy dogs examined, only four of them were infected with $T$. canis. In this study, the dogs examined were all adults.

In the present study, Dipylidium caninum and Ancylostoma caninum had high prevalence rates in each host, probably indicating that they require a certain population density in their hosts so as to maintain their host transmission potential (Anderson, 1993). Moreover, dogs generally have a wide feeding habit which makes them pick up helminthes ova as shown by the high number of dogs positive for helminthes in this present work. Dipylidium caninum and Ancylostoma caninum are potentially transmissible to man (Styles 1967; Flores and Uruchurtu, 1977 and Daralos, 1985).

The current study has clearly shown that dogs in Zaria harbor parasites, and so about $90 \%$ of the dog population may be contributing to the contamination of the environment with eggs of zoonotic helminthes. Thus, dog owners and those that have dogs around them are possibly at risk of infection with these helminthes. It is suggested that dog owners should always de-worm their dogs and monitor or check the movement of their dogs. Children are particularly susceptible and should wash their hands after playing with dogs and take their bath after playing in potentially contaminated playgrounds.

Dog Meat Wikipedia, the Free Encyclopedia last modified February $3^{\text {rd }} 2010$.

Ezeokoli, C. O. (1984). Prevalence of Gastrointestinal Parasites in pet dogs in Zaria, Nigeria. Nigerian Veterinary Journal, 13(1): 55-57.

Fabiyi, J.P. (1983). Gastrointestinal helminthes of dogs of the Jos Plateau, Nigeria. Tropical Animal Health and Production, 15: 137-138.

Fasanmi, F.E. (2004) Proposal for a 3 - year natural anti rabies campaign in Nigeria 2005-2007. A Circular to state commissioners.

Fashuyi, S.A (1981) Diagnosis of Gastrointestinal helminthes of dogs in Lagos area using the kato kate technique. Tropical Animal Health Production Africa, 29: 333-335. 
Flores, C. and Uruchurtu, A. (1977) Un estudio des 50 nectropsias en perros callejeros. Veterinaire. Mexico, 8:131-139.

Gavignet, B., Piarroux, R., Aubin, F., Millon, L. and Humbert, P. (2008). Cutaneous manifestations of human toxocariasis. Journal of American Acad. Dermatology, 59(6): 1031-1042.

Hill. I.R. Denham, D.A. and Scheltz, C.L. (1985). Toxocara canis larvae in the brain of a child. Transmission. Royal Society. Tropical Medicine and Hygiene. 79(3): 351-354.

Kim R.E. (2008). Dog Meat in Korea. A Socio- Legal Challenge" Animal Law, 14(3): 201-236.

Komtangi, M.C.N. (1998). The distribution of helmiknthes in the gastrointestinal tract of dogs in Zaria and the relationship between worm burden and egg outputs. M.Sc. Thesis, Ahmadu Bello University Zaria. 104 pp.

Levine, N.D. (1980). Nematode Parasites of Domestic Animals and of Man, Burgass Publishing Company, 477.

McCarthy, J. and Moore, T. (2000). Emerging helminth zoonoses. International Journal of Parasitology, 30:1351-1360.

Murray, S. (2007). Dogs Dinners Prove Popular in Nigeria. British Broadcasting (BBC) News website, Abuja last modified March 2007, 11:35 GMT.

Oduyemi, O.O. and Olayemi, M.F. (1977). An investigation into some causes of canine diarrhoea in Ibadan Journal of Small Animal Product 18: 543 - 547.

Olori, J. (2008), "Canis familiaris" (On-line), Digital Morphology. Accessed February 25, 2010 at http://digimorph.org/specimens/Canis_famili aris/bulldog.

Olufemi, B.E. and Bobade, P.A. (1979). Prevalence of gastrointestinal helminthes Parasites of dogs in Ibadan Nigeria. Nigerian Veterinary Journal, 8 (2); $68-70$.

Robertson, I.D., Irwin, P.J., Lymbery, A.J. and Thompson, R.C.A.(2000). The role of companion animals in the emergence of parasitic disease. International Journal of Parasitology, 30:1369-1377.

Schad, G.A. (1994). Hookworms: Pets to humans. Annual International. Medicine.. 120: 424435.

Smyth, J.D.(1994). Animal Parasitology Cambridge University Press. Cambridge. 327 - 511.

Soulsby, E.J.L. (1965). Textbook of Veterinary clinical Parasitology 1 Davis. company. 540.

Statistical Package for Social Sciences (SPSS) software.
Styles, T.(1967). Incidence of Toxocara canis and other helminthes Parasites of dogs in Mexico City. Journal Parasitology. 4: 822-823.

Tekdek, L.B. and Umoh, J.U. (1985). The effect of other gastrointestinal Parasites Season, breed, age and sex on hookworm in dogs in Zaria. Nigerian Veterinary Journal, 14: 23-27.

Traub, R.J., Robertson, I.D., Irwin, P. Mencke, N. and Thompson, R.C. (2002). The role of dogs in transmission of gastrointestinal parasites in a remote tea-growing community in northeastern India. American Journal of Tropical Medical Hygiene.67(5):539-545.

Umar, Y.A. (2009). Intestinal Helminthoses in Dogs in Kaduna Metropolis, Kaduna State, Nigeria, Iranian Journal of Parasitology, 4(1):34-39.

WHO, (1959). Joint Expert committee on Zoonoses second report. Tech. Rep. Ser. No 169. 